\title{
Uma voz que se propaga: ações de Social TV e propagabilidade através do The Voice US
}

\section{Mateus Vilela}

Doutor; Associação Beneficente da Indústria Carbonífera de Santa Catarina, Criciúma, SC, Brasil mateusdvilela@gmail.com

\section{Resumo}

Em um contexto em que as opções de entretenimento são cada vez maiores e de mais fácil acesso, a televisão tem buscado maneiras de fidelizar o público, bem como de atrair novos espectadores. A internet, que aparentava ameaçar a hegemonia da TV, tem sido uma grande aliada nessa tarefa, principalmente no uso das redes sociais. Nesse ambiente, o talent show norteamericano The Voice tem-se mostrado bastante eficiente em dialogar com a audiência, propiciando ações de Social TV e propagabilidade de conteúdos. Na busca por investigar as sinergias entre audiência, emissores e redes sociais, encontramos estratégias envolvendo aplicativos, vídeos de bastidores, spoilers, linguagem mais coloquial, hashtags e possibilidades de alteração do fluxo narrativo através de pesquisa bibliográfica e análise documental, tendo em vista a natureza do objeto empírico.

\section{Palavras-chave}

Televisão. Redes sociais. Social TV. Propagabilidade. The Voice.

\section{Introdução}

No atual contexto, é inegável que a televisão e os demais veículos tradicionais de comunicação estão sendo desafiados por tecnologias que ofertam opções mais segmentadas, sejam elas informacionais ou de entretenimento. Ainda assim, Castells (2000) acredita que as mídias de massa não serão eliminadas, mas sim transformadas pela internet, que se caracteriza pela interligação entre formatos de comunicação diversos com lógicas próprias. 
Mesmo que a internet não seja a sentença de morte da televisão, é inegável que seu poderio foi reduzido frente à ubiquidade que as tecnologias digitais oferecem. Com uma maior oferta de conteúdo, os canais passaram a contar com uma audiência cada vez menor e mais dispersa, que divide sua atenção com outras mídias. Até o momento, uma das poucas saídas encontradas pela TV para frear tal dispersão do público reside em uma aliança com as redes sociais.

Ainda assim, o desafio é complexo e envolve usar as redes sociais como mediação de audiência, além de organizar a conversação, estimular o compartilhamento e fidelizar os espectadores que procuram uma experiência cada vez mais personalizada. Tal comportamento é tratado por Machado e Vélez (2014) através da figura do interator. Para os autores, esse é o novo protagonista do cenário audiovisual, que forçou a mudança em direção a modelos de conteúdo que possam ser buscados e acessados em qualquer lugar e hora, bem como conteúdos que sejam de livre intervenção.

Todo esse processo fez com que a televisão deixasse de focar em si mesma e transferisse sua atenção ao público, como acredita Verón (2007). Prova disso é a proliferação do gênero reality show e a chegada de tecnologias que propiciam a interação dos usuários. Assistir a um determinado programa tem deixado de ser uma tarefa que envolve somente a TV. Cada vez mais, as redes sociais têm sido usadas como ferramentas de interação, seja entre usuários, seja para ressignificar conteúdos e alterar o fluxo das atrações. Partindo desse ambiente, o presente artigo busca analisar as técnicas de que a televisão se apropria para atrair - e fidelizar - os telespectadores, através das estratégias usadas pelo The Voice US - talent show da emissora National Broadcasting Companny (NBC).

Para tanto, apoiamo-nos na realização de uma pesquisa a partir do tensionamento de conceitos e autores vinculados às discussões. A partir da descrição do The Voice US, realizamos uma análise documental, tendo em vista a natureza do objeto empírico. No nível interpretativo, articulamos os dados coletados em questão às argumentações propiciadas pelo âmbito teórico, a fim de fornecer ao estudo "[...] a condição própria de cientificidade." (LOPES, 2010, p. 151).

\section{A mídia que se propaga e a Social TV}

Para impedir a dispersão do público e estimular a propagação dos conteúdos, os investimentos da televisão em publicidade aumentaram significativamente, dando origem 
ao que Epstein, Reeves e Rogers (2002) chamam de "era do branding". Tal etapa é marcada pela produção de textos para nichos específicos com grande preocupação com posicionamento de marca e de marketing.

Os públicos, diante desses investimentos, são caracterizados pelo autor como sendo ávidos pelos programas que gostam, tornando a experiência de assisti-los quase religiosa. Os textos, aos quais a audiência assiste, não seriam somente uma predileção, mas também uma autoafirmação passional - e este é o seu objetivo: construir conteúdos e ações de marketing que mantenham as pessoas fidelizadas diante da tamanha variedade de opções disponíveis.

Através do texto de Jenkins, Green e Ford (2014), entende-se os meios de comunicação tradicionais como componentes do que os autores intitulam de "mídia mainstream", que se diferencia da "mídia propagável". Entender os princípios da mídia propagável é também entender por que um conteúdo se espalha nas redes sociais e outros não. 0 que influencia na decisão do público no momento em que ele compartilha uma notícia em seu Facebook ou posta um tweet em seu Twitter? São tais decisões que "[...] estão remodelando o próprio cenário da mídia." (JENKINS; GREEN; FORD, 2014, p. 25).

Nesse cenário, a ação do público é bastante relevante, pois todo material propagado é refeito. Seja de modo figurado, quando o conteúdo é inserido em conversas por meio de diversas plataformas, ou de modo literal, quando o conteúdo é sampleado ${ }^{1}$ ou remixado. Logo, o público não é apenas mais um dado no processo da comunicação. Ele é um propagador e um gerador de conteúdo em um mundo que vive profundas mudanças no modo de comunicar-se. É peça essencial em um mundo onde o que não se propaga, morre.

Quando um conteúdo televisivo ultrapassa as barreiras do suporte e é discutido e transformado em mídias personalizadas, dá-se o nome de Social TV. Tal fenômeno tem um conceito impreciso. Ainda assim, tentativas de conceituação envolvem uma combinação de tecnologias em busca de uma experiência social mais intensa, como afirma Harboe (2008). Evangelia (2008), por sua vez, acredita que foi com a televisão digital interativa, um meio que permite a participação ativa dos espectadores, que o engajamento e a expressão pessoal começaram a tomar forma e ganharam popularidade.

\footnotetext{
${ }^{1}$ Samplear é "Utilizar trechos de registros sonoros anteriormente realizados para montar uma nova composição (quase sempre musical) por meio de um aparelho chamado sampleador. Gravar e processar sons (previamente gravados) por meio de um sampleador para conseguir outros. Montar uma composição ou arranjo musical com uso desse instrumento." (SAMPLEAR, 2015).
} 
O caráter social é bastante relevante, como já alerta o nome do fenômeno. De acordo com Marie-José Montpetit (2012), pesquisadora do Massachusetts Institute of Technology (MIT), a interação faz parte de toda a experiência televisiva, e a Social TV decorreria de duas tendências ligadas intrinsecamente: a interação social e a personalização, agregando ainda dois comportamentos distintos - o ativo e o passivo - no momento em que une a experiência passiva de entretenimento com a interação ativa da internet (MONTPETIT; KLYM; BLAIN, 2010).

Ainda sobre a sociabilidade, Schatz et. al. (2010) acreditam que, além de servir como catalisador para a interação entre os públicos, ela pode ser dividida em duas formas: uma direta e outra indireta. Na primeira, a televisão entra como fornecedor de contexto e a sociabilidade acontece paralela à exibição do programa; já na segunda, ela pode acontecer antes ou depois da exibição do programa e é mobilizada por fóruns, por exemplo.

Experimentos revelaram que os indivíduos se engajam mais através do contato com uma audiência virtual. Segundo Zwaaneveld (2009), alguns usuários relataram assistir a não somente seus programas favoritos, mas também a outros conteúdos somente pelo fato de outros o estarem fazendo. Afirmaram ainda participar de pequenas conversas sobre os programas durante o intervalo, compartilhando interesses em comum. Adotaram, por fim, uma postura de lean-forward, de prontidão, de alerta para interagir, comentar e publicar, como afirma Johnson (2012).

A experiência de Social TV levou Montpetit, Klym e Blain (2010) a relacionarem tal fenômeno com os primórdios da televisão. Para os autores, há uma redescoberta do ato de assistir à TV como momento compartilhado, referenciando às décadas em que o aparelho ainda era bastante caro e, portanto, havia apenas um em cada residência.

Os conceitos de propagabilidade e Social TV, em última instância, são interligados. Se um conteúdo propaga-se, ele gera comentários nas redes sociais - e se esse conteúdo for televisivo, ele propicia a Social TV. Em ambos fenômenos, o público desempenha um papel ativo na propagação: são os seus valores, interesses e propósitos que definem o que tem valor ao ponto de merecer ser propagado. Quando a mídia se propaga, ela não somente consegue alçar novos voos e encontrar novos ares, como também promover um profundo engajamento nas comunidades de nicho (JENKINS; GREEN; FORD, 2014, p. 48).

Entretanto, ainda que o público tenha a decisão final sobre o que se propagará ou não, bem como sobre o que vai ser comentado nas redes sociais, o estímulo por parte das emissoras tem feito a diferença. Em um ambiente no qual a quantidade de conteúdo 
disponível é imensurável, os programas de televisão têm buscado atrativos para que os espectadores se sintam cada vez mais prestigiados e apegados aos textos televisivos.

\section{As estratégias de Social TV e de propagabilidade do The Voice US}

Criado pelo produtor John de Mol e baseado no formato holandês The Voice of Holland, o talent show norte-americano The Voice estreou em 2011 e logo se tornou um sucesso de público e crítica (THE VOICE US, 2011). Contando com um time de técnicos oriundos do mundo da música, inicialmente Adam Levine (Maroon 5), Blake Shelton, CeeLo Green e Christina Aguilera, o programa oferece, ao candidato vencedor, o prêmio de 100.000 dólares, além de um contrato com a gravadora Universal Music.

Dividido em etapas, a primeira consiste em blind auditions ${ }^{2}$, momento no qual os técnicos formam seus times enquanto estão sentados de costas para o palco, sendo guiados somente pela habilidade vocal dos candidatos. Quando um técnico se interessa pela voz do competidor, ele deve apertar o botão de $I$ want you ${ }^{3}$ para que sua cadeira vire, revelando, além de seu interesse, a fisionomia do cantor. Se mais de um mentor quiser o mesmo participante, cabe a este decidir de que time fará parte.

Terminadas as audições, o segundo estágio consiste em batalhas entre os membros de um mesmo time, que duelam cantando uma mesma música. 0 melhor intérprete é salvo, enquanto o outro é eliminado da competição, reduzindo os times à metade. Os vencedores dos battle rounds são, então, encaminhados para o round de nocautes. Desta vez, cada integrante escolhe uma música e apresenta-a em frente aos técnicos, que novamente eliminam metade dos competidores restantes.

Os vinte candidatos que passaram pelas três fases anteriores, cinco de cada time, vão então para os live playoffs, quando novamente apresentam uma música de sua preferência. Cada técnico salva dois cantores de seu time, e o público salva um terceiro através de votação. Os doze sobreviventes dessas etapas cantam ao vivo todas as segundas-feiras, e, nas terças-feiras, os dois cantores com menor quantidade de votos por telefone, internet e download ${ }^{4}$ são eliminados. Esse processo segue até que reste apenas um cantor, que será consagrado o vencedor da edição e "a voz" da América.

\footnotetext{
${ }^{2}$ Audições às cegas, em tradução livre.

${ }^{3}$ Eu quero você, em tradução livre.

4 Parte da votação consiste na venda de canções no iTunes. Quanto mais a música do candidato for comprada, mais votos ele terá.
} 
Um dos motivos que fez essa competição musical, que já tem mais de doze edições, tornar-se tão popular reside no uso das redes sociais para impulsionar a atração. Desde o começo, além das votações por telefone, o programa disponibiliza a possibilidade de votar através do The Voice App, presente tanto na loja virtual da Apple quanto na loja para aparelhos Android. A aparência do aplicativo pode ser visto na Figura 1.

Figura 1 - The Voice App
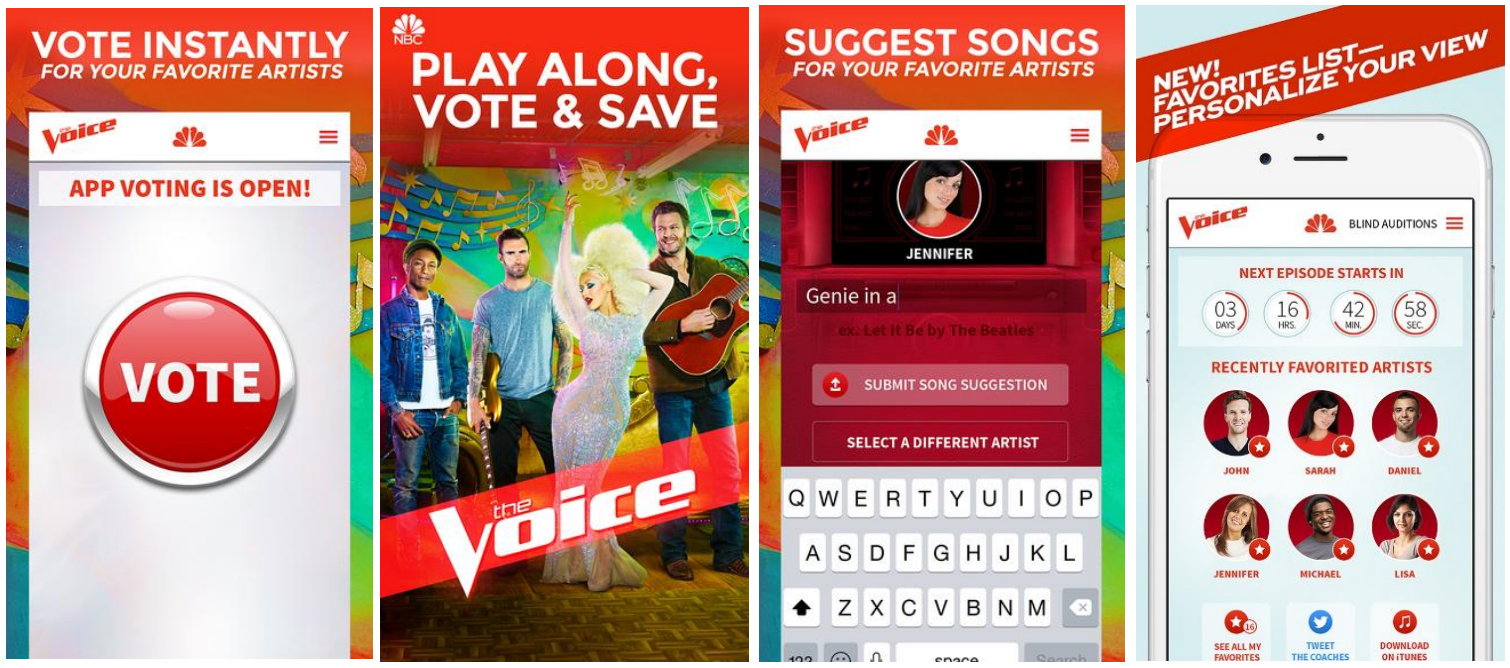

Fonte: The Voice (2014).

As opções do aplicativo incluem desde votar no seu candidato preferido, para que ele seja salvo e possa seguir na competição, até sugerir canções para os participantes, valendose ainda de uma contagem regressiva para os novos episódios. Através do The Voice App, é possível ter acesso aos links para comprar as músicas apresentadas no programa 5 , além da construção de um ranking pessoal com os participantes favoritos e do contato com outros fãs da atração.

A interação com a audiência, no entanto, vai além do aplicativo. Nas redes sociais, principalmente no Facebook, a página do reality show é bastante ativa, e - diante do fato de que, das audições às cegas até a fase de nocautes, o programa não é ao vivo - é costumeiro que sejam antecipadas algumas performances antes mesmo de serem veiculadas na televisão. 0 The Voice US acaba por fornecer, então, spoilers ${ }^{6}$ sobre si mesmo, com o objetivo de aumentar o interesse na atração.

\footnotetext{
5 A venda de música também gera votos para os candidatos.

${ }^{6}$ Antecipar acontecimentos em um programa de televisão, estragar a surpresa.
} 
Outra estratégia para manter a audiência cativa no intervalo entre os episódios envolve a divulgação de vídeos exclusivos dos bastidores e cenas deletadas, além de conteúdos criados para serem exibidos somente nas redes sociais, como mostra a Figura 2.

Figura 2 - Publicações do The Voice US no Facebook
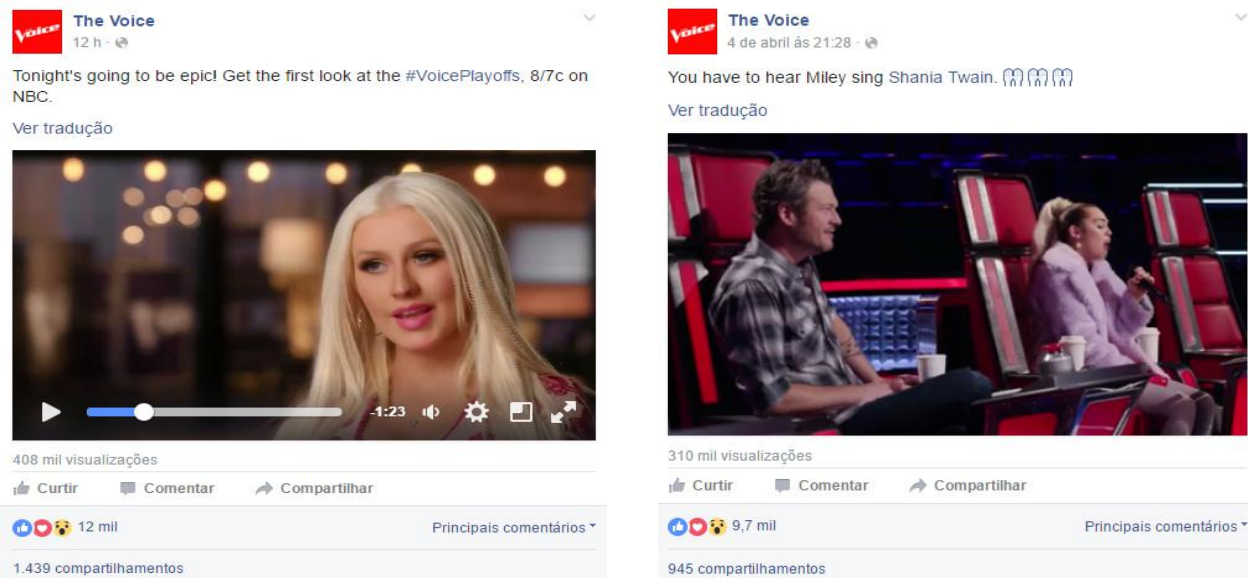

Fonte: NBC The Voice (2014).

Uma prática tipicamente encontrada na atividade dos fãs pode ser vista nas estratégias de fidelização construídas pelo programa. Trata-se da ressignificação imagética para construção de novos sentidos e novos significados, normalmente com tom jocoso, buscando a diversão, como afirma Fiske (1992). Mesmo que não seja uma produção da audiência, tais imagens ajudam a divulgar a atração através do compartilhamento, criando ainda outros sentidos além dos propostos pelo The Voice US, como exemplifica a Figura 3.

Figura 3 - Apropriações do The Voice US no Facebook
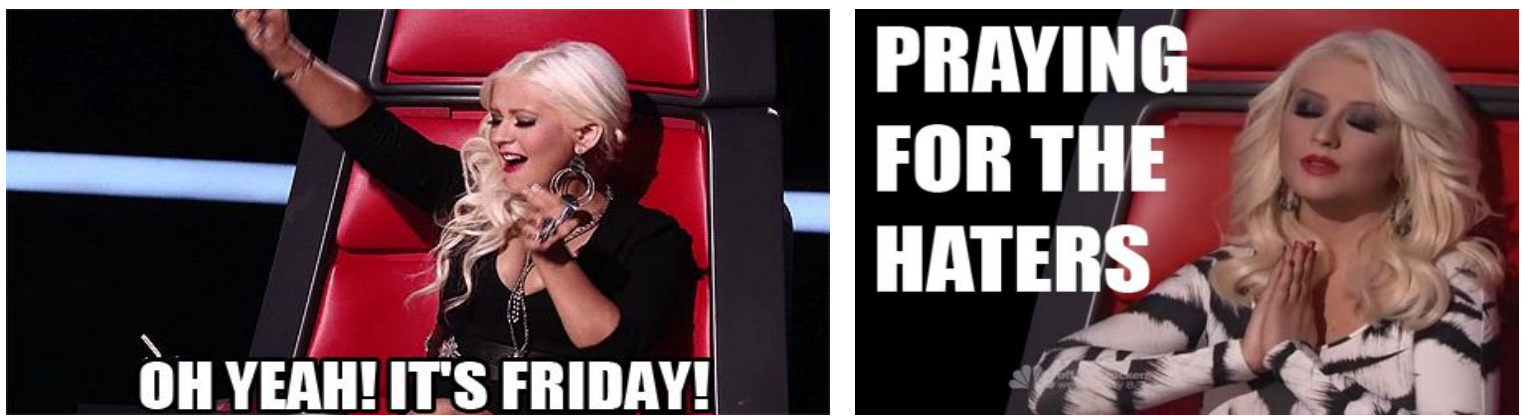

Fonte: NBC The Voice (2014). 
Mesmo que a instância da produção tenha se apropriado da ressignificação com fins lucrativos, esse comportamento mostra que alguns fãs não se contentam mais em somente assistir, mas realizam um investimento emocional e de tempo maior, tornando-se participantes ativos no processo de transformação da cultura midiática (JENKINS, 2006). No livro A invenção do cotidiano, Certeau (1994) trabalhou com o conceito de "atividade de caça", metáfora usada para designar a ação de sujeitos subordinados que se apropriam de conteúdos e os ressignificam de modo a satisfazer suas necessidades, conseguindo assim fugir do poder da mídia. Em outras palavras, por mais que a indústria midiática tente controlar a recepção, ela é indomável. Ressignifica e subverte à sua vontade; entende o que quer e como quer.

Outro elemento apropriado pelo programa, que cria um incentivo à conversação nas redes sociais, é o uso de hashtags, como mostra a Figura 4. Símbolo do Twitter, e mais recentemente incorporada pelo Facebook, essas formas gráficas atuam como indexadores de assuntos ou tópicos, agregando todos os tweets que as contém em um mesmo fluxo, no qual é possível observar a formação de uma comunidade ao redor desse mesmo tema. 0 uso de tais sinais gráficos possibilita ao usuário acompanhar toda a discussão em torno de um tópico em tempo real.

Figura 4 - Uso de hashtags no The Voice US
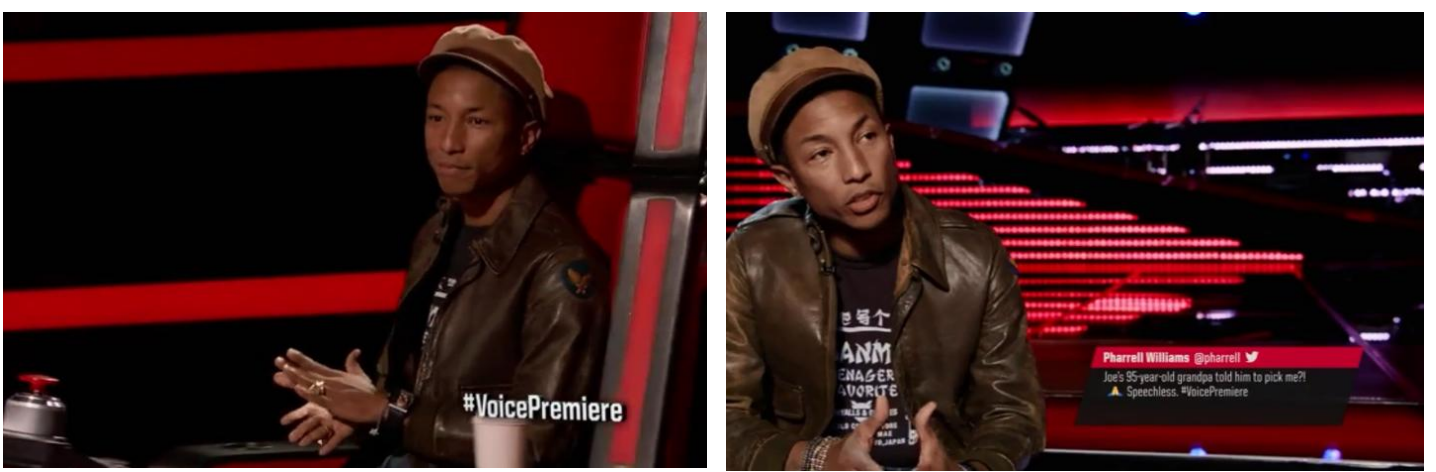

Fonte: The Voice US (2011).

Através das hashtags, o Twitter consegue conectar tweets a temas maiores, grupos específicos e pessoas. Segundo Murthy (2013), essa é uma forma única de conectar indivíduos diferentes e que não se conhecem. Com base no uso dessas palavras-chave, o sistema cria uma lista dos dez assuntos mais comentados do momento no país do usuário e 
no mundo - os chamados Trending Topics, que servem como um termômetro dos temas mais debatidos do dia.

A $N B C$, emissora que veicula o talent show, exibe ainda os comentários feitos no Twitter pelos jurados da atração, como visto na Figura 4, promovendo não somente a sua conta, mas a atração. A ação incentiva ainda a chance, mesmo que remota, dos técnicos conversarem com a audiência.

Se a definição de hashtags específicas já é um estímulo à conversação em rede, ter as celebridades do mundo da música comentando o programa é um incentivo ainda maior ao compartilhamento de opiniões sobre o The Voice US. Uma situação semelhante tem feito a série Scandal (2012), como afirma o The New York Times.

Toda quinta-feira desde a estreia do show, a maioria do elenco de Scandal tem usado o Twitter para realizar comentários enquanto os episódios vão ao ar. A presença do elenco nas mídias sociais - que, segundo dados da Nielsen, inspira centenas de milhares de tweets de pessoas que também estão assistindo à série - tem se refletido na relação do programa com sua audiência. (MANJOO, 2015, tradução nossa77).

Um dos elementos mais característicos do programa, e que une a experiência de assistir aos episódios ao mesmo tempo em que são exibidos na televisão com a interação nas redes sociais, é o recurso Instant Save. Nas noites de terça-feira, quando são anunciados os candidatos salvos pela audiência, informa-se também os três competidores com a menor quantidade de votos. Tais cantores apresentam, então, mais uma canção, e o público, através do Twitter, vota naquele que acredita ser o mais capaz de seguir na competição. 0 próprio site do The Voice US explicita o funcionamento da estratégia.

Na fase de apresentações ao vivo, os 12 artistas vão competir a cada semana um contra o outro durante uma transmissão ao vivo. A audiência votará para salvar seus artistas favoritos. Três artistas com o menor número de votos serão elegíveis para o 'Instant Save'. Esses artistas vão executar uma nova canção que representa por que devem permanecer no show. Em seguida, os Estados Unidos terão a oportunidade de salvar seu candidato preferido twittando \#VoiceSave junto com o nome do artista. Os dois cantores com o menor número de votos serão enviados para casa, a

\footnotetext{
7 Do original: Every Thursday since the show's premiere, most of the "Scandal" cast and crew have used Twitter to add live commentary that runs during the broadcast. The cast's social media presence - which, according to the ratings firm Nielsen, inspires hundreds of thousands of tweets from viewers during every broadcast - has been credited with deepening the program's relationship with its audience.
} 
cada semana. No final, um será nomeado "a voz" e receberá o grande prêmio de um contrato de gravação. (THE VOICE, 2014, tradução nossa ${ }^{8}$, doc, não paginado).

Dessa forma, através do uso do Twitter, os fãs do programa podem decidir quem continua na competição, vide Figura 5. Diferente da votação regular do show, por telefone ou por internet, que disponibiliza 24 horas para que a audiência vote, o Instant Save exige que o usuário esteja assistindo ao vivo e, ao mesmo tempo, conectado, pois o tempo que a emissora contabiliza os tweets é de aproximadamente cinco minutos.

Figura 5 - Instant Save no The Voice US

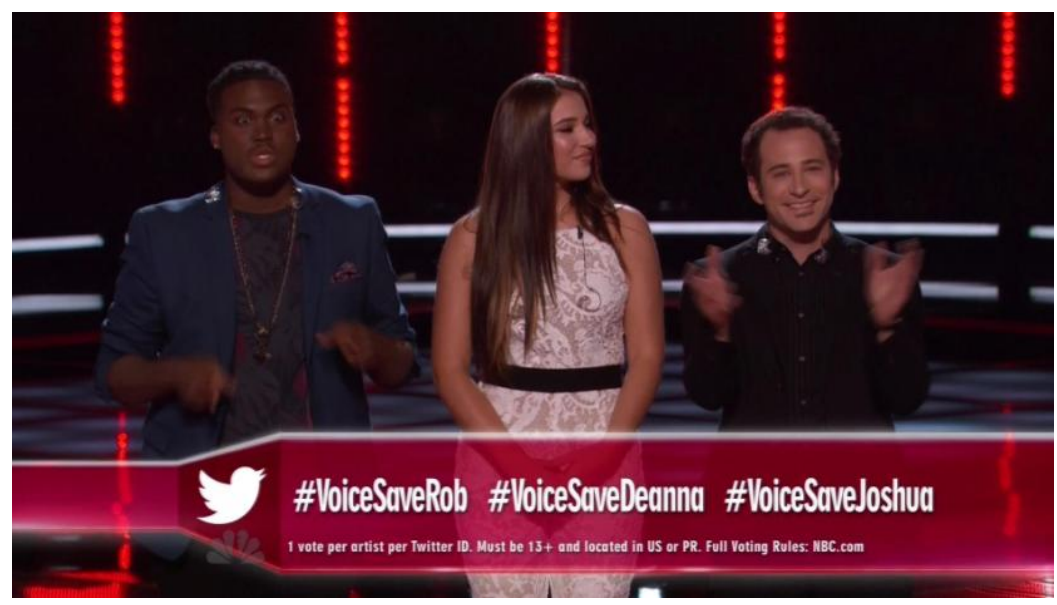

Fonte: The Voice US (2011).

Já que se trata de um fenômeno recente, ainda não é possível saber com exatidão a colisão entre as duas telas, ou mesmo a exata forma com que trabalham, mas estudos recentes comprovam que existe uma certa sinergia entre a TV e as redes sociais:

[...] de fato existe uma correlação entre as plataformas e a migração de sujeitos entre elas. Conforme pesquisa publicada no dia 6 de agosto de 2013 - que analisou 221 episódios de diferentes programas americanos que vão ao ar no horário nobre - a correlação entre as mídias aponta uma clara influência entre o buzz gerado no Twitter sobre a audiência dos programas e vice-versa. 0 aumento da audiência produziu $48 \%$ de buzz a

\footnotetext{
${ }^{8}$ Do original: In the final live performance phase of the competition, the top 12 artists will compete each week against each other during a live broadcast. The television audience will vote to save their favorite artists. Three artists with the lowest number of votes will be eligible for the "Instant Save." These artists will each perform a new song that represents why they should earn the save. Then, America will have the opportunity to save their favorite performer by tweeting out \#VoiceSave along with the artist's name. The two singers with the lowest number of votes will be sent home each week. In the end, one will be named "The Voice" and will receive the grand prize of a recording contract.
} 
mais nos episódios analisados e o aumento no número de tweets fez a audiência subir em 29\% das atrações analisadas. (BORGES; SIGILIANO, 2013, p. 116).

Cientes dessa sinergia, e tendo que investir em novos modos de fidelização e manutenção de uma audiência cada vez mais dispersa diante de muitas opções, o The Voice US mostra-se pioneiro em utilizar uma variada gama de recursos focando, principalmente, nas redes sociais. Não somente o programa busca atrair o público, mas ele começa a proporcionar uma interação desse com os espectadores, além de apropriar-se de elementos característicos das ações de fãs.

\section{Considerações finais}

Em última instância, as estratégias de Social TV e propagabilidade do The Voice US apropriam-se de locais e atividades características dos usuários, tornando-as aparatos de divulgação. Tal afirmativa pode ser ratificada, por exemplo, no momento em que o programa decide quais hashtags exibir nos episódios, o que serve de publicidade ao mesmo tempo que, implicitamente, abre mão da total atenção dos espectadores para com a televisão. Assim, aceita e incentiva o perfil multitarefas do público.

Da mesma forma, na apropriação e posterior ressignificação imagética feita pelo programa, ele coloca-se na condição de fã ao construir novos sentidos para o conteúdo da atração. Essa atividade ajuda o The Voice US a criar uma relação de afetividade e reconhecimento com a audiência. Vale ressaltar que o afeto é bastante relevante no momento em que a relação do fandom ${ }^{9}$ com a cultura acontece - é o afeto que determina a quantidade de energia que o sujeito disponibilizará ao programa, bem como a qualidade desse sentimento.

No que tange ao aplicativo, seu maior triunfo consiste em agrupar os fãs mais devotos do programa, ao passo que oferece um panorama completo da competição e a possibilidade de simular a função de técnico. Funciona como uma gratificação pela devoção, além de servir como ponto de encontro do fandom e fomentar, ainda, o investimento afetivo e financeiro por parte do usuário.

A gratificação acontece também no Facebook, através dos vídeos de bastidores e dos materiais construídos exclusivamente para a internet. São conteúdos que permitem um

9 Termo usado para referir-se a uma comunidade de fãs. 
olhar mais invasivo e menos editado, servindo como recompensa para quem segue a página. Ademais, servem como conteúdo de ponte, ou seja, tornam a espera por novos episódios menos demorada, não deixando que a audiência perca o interesse ou mesmo se esqueça do The Voice US e atuando como um conteúdo que auxilia na fidelização.

Por fim, o recurso Instant Save traz uma questão bastante relevante no que tange ao fenômeno de Social TV: a concomitância com a veiculação do programa. Mesmo com a potencialização da chamada TV on demand ${ }^{10}$, a appointment television ${ }^{11}$ ganha força pelo fato de que o indivíduo necessitaria estar assistindo ao mesmo tempo em que os demais, via broadcasting, para caracterizar uma experiência de interação tanto com outros espectadores quanto na definição dos candidatos salvos na competição. É um poder dado aos usuários das redes sociais, mas que exige uma compensação em termos de números de audiência.

Ainda que o The Voice US crie estratégias focadas nas "atividades de caça" da audiência, ela seguirá ressignificando os produtos de acordo com as experiências pessoais de cada um. Em última instância, o público ressignificará as próprias ressignificações propostas pela atração. Ainda assim, as ações do talent show analisado constroem uma interessante visão sobre onde o público está e quais são as novas formas de aproximar-se desse novo perfil de espectadores.

\section{Referências}

BORGES, Gabriela; SIGILIANO, Daiana Maria Veiga. Social TV: a sinergia entre os as hashtags e os índices de audiência. Revista Geminis, São Carlos, v. 4, n. 2, p. 106-119, 2013.

CASTELLS, Manuel. A Sociedade em rede. São Paulo: Paz e Terra, 2000. v. 1.

CERTEAU, Michel. A invenção do cotidiano. Petrópolis: Vozes, 1994.

EPSTEIN, Michael C.; REEVES, Jimmie; ROGERS, Mark. The Sopranos as HBO brand equity. In: LAVERY, David (Ed.). This thing of ours: investigating The Sopranos. New York: Wallflower, 2002. p. 42-57.

EVANGELIA, Mantzari. The implementation of social interactive television. In: UXTV 2008, 1., 2008, Silicon Valley. Proceedings... Silicon Valley, 2008, Social TV Workshop Position Papers.

FISKE, John. The cultural economy of fandom. In: LEWIS, Lisa A. (Ed.). The adoring audience: fan culture and popular media. London: Routledge, 1992. p. 30-49.

10 TV sob demanda.

11 TV com hora marcada, ou seja, definida por uma grade de programação. 
HABOE, Gunnar. The TV is watching you. In: UXTV 2008, 1., 2008, Silicon Valley. Proceedings... Silicon Valley, 2008. Social TV Workshop Position Papers.

JENKINS, Henry. Cultura da convergência. São Paulo: Aleph, 2006.

JENKINS, Henry; GREEN, Joshua; FORD, Sam. Cultura da conexão: criando valor e significado por meio da mídia propagável. São Paulo: Aleph, 2014.

JOHNSON, Steve. Tudo que é ruim é bom para você: como os games e a TV nos tornam mais inteligentes. Rio de Janeiro: Zahar, 2012.

LOPES, Maria Immacolada Vassallo de. Pesquisa em comunicação. São Paulo: Loyola, 2010.

MACHADO, Arlindo; VÉLEZ, Marta Lucía. Fim da televisão? In: CARLÓN, Mario; FECHINE, Yvana (Org.). 0 fim da televisão. Rio de Janeiro: Confraria do Vento, 2014. p. 54-76.

MANJOO, Farhad. Social media takes television back in time. New York Times, New York, 3 Oct. 2015.

MONTPETIT, Marie-José. Building a new digital highway and a global living room: MarieJose Montpetit at TEDxSilkRoad. In: TEDxSILKROAD, 2012, Istanbul.

MONTPETIT, Marie-José; KLYM, Natalie; BLAIN, Emmanuel. The future of mobile TV: when mobile TV meets the internet and social networking. In: MARCUS, Aaron; CEREIJO ROIBÁS, Anxo; SALA, Riccardo (Ed.). Mobile TV customizing content and experience. London: Springer, 2010. p. 305-326.

MURTHY, Dhiraj. Twitter: social communication in the twitter age. Cambridge: Polity Press, 2013.

NBCTHEVOICE. [Facebook]. 2014.

SAMPLEAR. In: DICIONÁRIO informal. 2015.

SCANDAL. Criação: Shonda Rhimes. New York: American Broadcasting Company, 2012. Duração 330 min. Season 1.

SCHATZ, Raimund et al. "What are you viewing?": exploring the pervasive social TV experience. In: MARCUS, Aaron; CEREIJO ROIBÁS, Anxo; SALA, Riccardo (Ed.). Mobile TV customizing content and experience. London: Springer, 2010. p. 255-290.

THE VOICE. About [the show]. 2014. Portal The Voice na NBC.com.

THE VOICE US. Criação: John de Mol. Direção: Alan Carter. New York: National Broadcasting Company, 2011. 
VERÓN, Eliseo. Semiótica come sociosemiótica: intervista a Eliseo Verón. In: SCOLARI, Carlos; BERTETTI, Paolo (Ed.). Mediamerica: semiótica e analisi dei media a America Latina. Torino: Cartman, 2007.

ZWAANEVELD, Jarno. Comparing social TV approaches: a look into enjoyment, presence and awareness. In: TWENTE STUDENT CONFERENCE ON IT, 11., 2009, Enchede. Papers.

Enschede: University of Twente , 2009.

\title{
A voice that spreads: Social TV and spreadable media through The Voice US
}

\begin{abstract}
In a context in which entertainment options are becoming larger and easier to access, television has searched for strategies to retain the public and attract a new audience. The internet, which seemed to threaten the hegemony of TV, has been a great ally in this task, especially in the use of social networks. In this context, the talent show The Voice has been quite effective in the dialogue with the audience enabling Social TV and spreadable content. In the search to investigate the synergy between audience, producers and social media, we found strategies involving apps, backstage videos, spoilers, colloquial language, hashtags and possibilities of altering the narrative flow through a bibliographical research and documentary analysis, considering nature of the empirical object.
\end{abstract}

\section{Keywords}

Television. Social media. Social TV. Spreadable media. The Voice US.

Recebido em 18/11/2017

Aceito em 03/04/2018 